\title{
A Straightforward Estimation Approach for Determining Parasitic Capacitance of Inductors during High Frequency Operation
}

\author{
Khalil Kanzi*, Hanidreza R. Nafissi** and Majid Kanzi***
}

\begin{abstract}
A straightforward method for optimal determining of a high frequency inductor's parasitic capacitance is presented. The proposed estimation method is based on measuring the inductor's impedance samples over a limited frequency range bordering on the resonance point considering $\mathrm{k}-\mathrm{dB}$ deviation from the maximum impedance. An optimized solution to $\mathrm{k}$ could be obtained by minimizing the root mean squared error between the measured and the estimated impedance values. The model used to provide the estimations is a parallel RLC circuit valid at resonance frequency which will be transferred to the real model considering the mentioned interval of frequencies. A straightforward algorithm is suggested and programmed using MATLAB which does not require a wide knowledge of design parameters and could be implemented using a spectrum analyzer. The inputs are the measured impedance samples as a function of frequency along with the diameter of the conductors. The suggested algorithm practically provides the estimated parameters of a real inductance model at different frequencies, with or without design information. The suggested work is different from designing a high frequency inductor; it is rather concentration of determining the parameters of an available real inductor that could be easily done by a recipe provided to a technician.
\end{abstract}

Keywords: High frequency inductor, parasitic capacitance, EMI filter

\section{Introduction}

The real model of an inductor is shown in Fig. 1 [1]. The resistance $R_{p a r}$ represents the total winding losses and core losses which are modeled in series with the winding inductance [2-4]. Also, the inductance $L_{\text {ind }}$ is the total self-inductance of each turn plus the mutual inductances between the turns $[5,6]$.

The parasitic Capacitance $C_{p a r}$ defines the capacitances between the turns, the layers, as well as the winding and the frame or the shield.

Determinations of these parameters are based on the dimensions and specifications of the materials, where their frequency-dependent values were considered in many literatures [3, 5, 7-11]. Changing the frequency affects the performance of the circuit especially by the parasitic capacitance [12].

However, the permittivity of most materials is fixed up to the conductive noise frequency $(30 \mathrm{MHz})$, resulting in insignificant capacitance change. Meanwhile, the

* ACECR, K.N. Toosi Branch, Tehran, Iran kanzi@ gmail.com)

** ACECR, K.N. Toosi Branch, Tehran, Iran r.nafissi@gmail.com)

***ACECR, K.N. Toosi Branch, Tehran, Iran (mjdknz@gmail.com)

Received 10 June 2014; Accepted 12 July 2014 inductance will significantly be affected by varying the frequency. Change of frequency varies the inductance due to the magnetic circuit permeability change, the skin effect and proximity effect $[5,13]$.

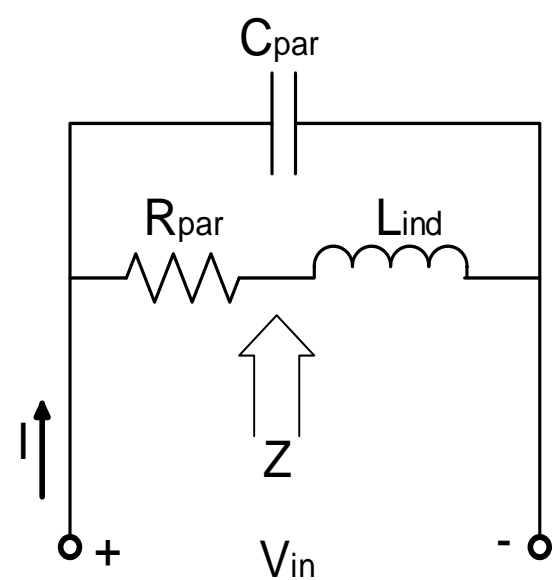

Fig. 1. Frequency model for an inductor

Both $R_{p a r}$ and $C_{p a r}$ have undesirable effects on the performance of the inductor, especially for high frequency applications [1]. Hence, there are two main methods to reduce the parasitic capacitance of an inductor; first, using a proper design of high frequency inductor. In this method, 
the minimum parasitic capacitance is achieved by proper choice of the core type, dimensions, the number of layers and turns as well as arranging the turns and insulation [5, 7-10, 14]. In [15], an approximation for the Jill-Atherton model of hysteresis loop has been propounded by ANFIS (Adaptive-Network-based Fuzzy Inference System) software. This model is useful to estimate the effective resistance related to the core losses. It should be noted that altering the designing parameters only results in reducing parasitic capacitance down to a certain level. Moreover, an additional completed inductor is required to be used in many cases.

The second method is based on lowering the parasitic capacitance effect of an inductor by designing a supplementary circuit [16]. This circuit is composed of an additional inductor along with a compensating capacitor. The ratings of the additional circuit are calculated based on the parasitic capacitance of the main inductor. Hence, in order to implement the second method, it is necessary to obtain parameters of the main inductor beforehand (in particular the parasitic capacitance). Further, these parameters should be given accompanied with their frequency changes [17]. Moreover, the parasitic capacitance may not be measured directly using LRC meters because most LRC meters apply an RL or RC circuit in parallel or in series with the main circuit, measuring the parameters of the resultant equivalent circuit with frequency sweep or impedance analyzer. In practice, direct measurement gives different results from those of the real parameters.

This paper introduces a straightforward method to estimate the parameters of a real inductor based on the behavior of the inductor at different frequencies. The method is based on measuring the impedance magnitude over a limited range of frequencies which encompasses a bandwidth around the resonance frequency of inductor. Then, the proposal analyses the measured impedance magnitudes, working out the resistance, inductance and capacitance using the well-known circuit theory on an equivalent circuit model of Fig. 2 at resonance frequency and then transferred to parameters of Fig. 1 at this point. Parameters of Fig. 1 should be modified over the measured frequency range from which the estimation is conducted. Minimization of the mean root squared error between the measured and estimated impedances is considered as a basis to measure the validity and reliability of the estimation method. Besides, the model, used to provide the estimations, is a parallel RLC circuit valid at resonance frequency which will be transferred to the real model considering the mentioned interval of frequencies. Several inductors, both single-layer and multilayers, were implemented. Then, the estimation suggestion was applied to these inductors in order to find out the parameters of the real models. Comparison of the measured impedances with those of the estimated ones validates the suggested method of determination of real parameters at various frequencies.

\section{Parallel RLC circuit, equal to real inductor circuit}

Assume the real inductor model, shown in Fig. 1, is represented by an equivalent parallel RLC illustrated in Fig. 2. The parasitic capacitance remains the same in both models. Meanwhile, other frequency-dependent parameters in Fig. 2 can be derived as functions of parameters in Fig. 1 using the simple circuit relationships as follows (See appendix A for a detailed derivation):

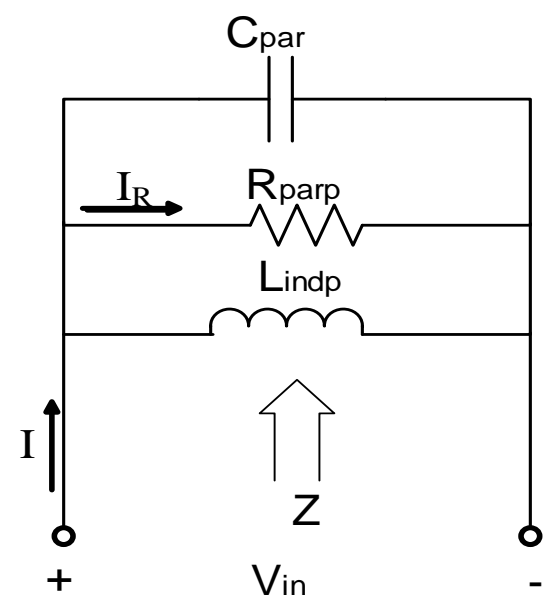

Fig. 2. Parallel RLC model for an inductor

$$
\begin{aligned}
& R_{\text {par }}=\frac{R_{\text {parp }} \omega^{2} L_{\text {indp }}^{2}}{R_{\text {parp }}^{2}+\omega^{2} L_{\text {indp }}^{2}} \\
& L_{\text {ind }}=\frac{R_{\text {parp }}^{2} L_{\text {indp }}}{R_{\text {parp }}^{2}+\omega^{2} L_{\text {indp }}^{2}} \\
& R_{\text {parp }}=\frac{R_{\text {par }}^{2}+\omega^{2} L_{\text {ind }}^{2}}{R_{\text {par }}} \\
& L_{\text {indp }}=\frac{R_{\text {par }}^{2}+\omega^{2} L_{\text {ind }}^{2}}{\omega^{2} L_{\text {ind }}}
\end{aligned}
$$

Frequency-dependent relationships, apart from the resistance, indicate that the estimation of parameters should include the frequency dependency upon model changing. Typical variations of the impedance of an inductor against frequency are depicted in Fig. 3, showing the resonance 
frequency and a bandwidth in which the impedance is lowered down by $1 / \mathrm{k}$.

While Zmax relates to the resonance frequency, $\mathrm{Zmax} / \mathrm{k}$ corresponds to two frequencies which their related impedances are $20 \log (\mathrm{k})$ in $\mathrm{dB}$ smaller than that of the resonance frequency (e.g. for $k=\sqrt{ } 2$, the well-known $-3 \mathrm{~dB}$ bandwidth is obtained). The information associated with the maximum of impedance, resonance frequency and $-3 \mathrm{~dB}$ bandwidth can be obtained using a high frequency impedance analyzer for an inductor. The lowest impedance that intersects twice the impedance curve in Fig. 3 is $\mathrm{Zmin}$ (still a bandwidth is associated with $\mathrm{Zmin}$ ). Then, the value $M$ can be calculated by finding the ratio of $\mathrm{Zmax}$ over $\mathrm{Zmin}$ in which $\mathrm{k}$ is limited to the range $[1, \mathrm{M}]$. Also, a parallel RLC circuit introduces the maximum impedance at resonance frequency, i.e. $Z \max =$ Rparp [18]. When the resistance changes with frequency, then the maximum impedance is given by:

$$
\left|Z\left(f=f_{0}\right)\right|=Z_{\max }=R_{\text {parp }}\left(\omega_{0}\right)
$$

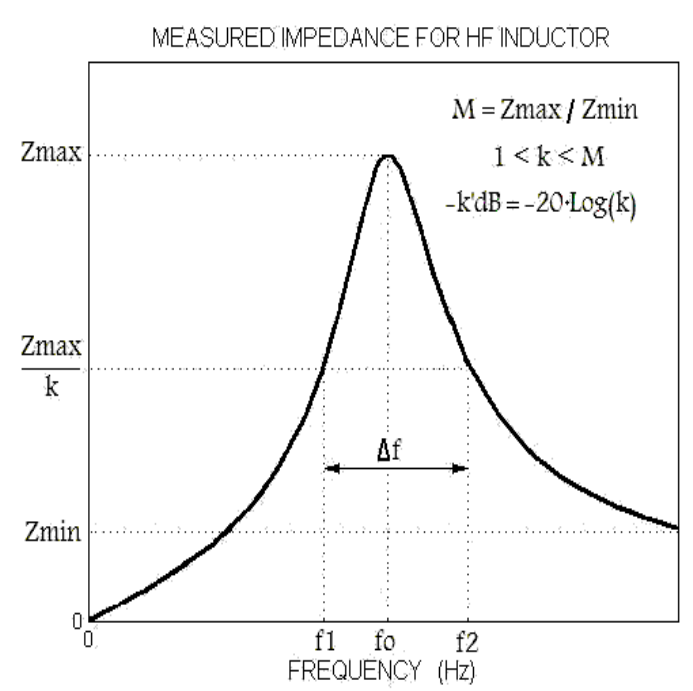

Fig. 3. Parallel RLC circuit impedance range

Also, the transfer function IR/I will be equal to one at the resonance frequency. In general, the normalized impedance as a transfer function is worked out based on the resonance frequency $\omega 0$ and the quality factor $\mathrm{Q}$. This transfer function can be expressed as follows (See appendix A for detailed description):

In the parallel resonance circuit, the circuit input current I and the resistance current IR will be equal, and thus if we consider the circuit transfer function as the resistance to circuit input current ratio IR/I, then the value of the transfer function at the resonance frequency will be equal to one. The circuit transfer function relation may be specified based on the $\omega 0$ resonance frequency and also the Q quality factor [8]. The significant point is that to the circuit relations, it may be easily proved that such value is equal to the normalized impedance value. Thus, where the impedance value reaches to $1 / \mathrm{k}$ of the maximum value, we have $|H(\omega)|=(1 / k)$.

In such case, the value of attenuation around the resonance frequency will be $-k^{\prime} d B=-20 \log (k)$. The transfer function or the normalized impedance as follows, and solving (6) for $\left|\mathrm{Z}_{\mathrm{PU}}(\omega)\right|=1 / \mathrm{k}$, results in the following relationship:

$$
\begin{gathered}
|H(\omega)|=\left|Z_{P U}(\omega)\right|=\frac{|Z(\omega)|}{Z_{\max }}=\frac{1}{\left[1+Q^{2}\left(\frac{\omega}{\omega_{0}}-\frac{\omega_{0}}{\omega}\right)^{2}\right]^{0.5}} \\
\frac{\omega}{\omega_{0}}=\sqrt{1+\frac{k^{2}-1}{4 Q^{2}}} \pm \frac{\sqrt{k^{2}-1}}{2 Q}
\end{gathered}
$$

Then, for high quality factors, (7) can be approximated as below (see appendix A for detailed description):

$$
\frac{\omega}{\omega_{0}}=1 \pm \frac{\sqrt{k^{2}-1}}{2 Q}
$$

From these two obtained frequencies, the lower frequency $\omega_{1}$ and the high frequency $\omega_{2}$, the bandwidth $\Delta \omega$ around $\omega_{0}$ can be found as follows:

$$
\Delta \omega=\omega_{2}-\omega_{1}=\frac{\omega_{0}}{Q}=2 \alpha=\frac{\sqrt{k^{2}-1}}{R_{\text {parp }}\left(\omega_{0}\right) \cdot C_{p a r}\left(\omega_{0}\right)}
$$

Since $Q \triangleq\left(\omega_{0} / 2 \alpha\right)=\omega_{0} R_{\text {parp }} C_{\text {par }}$, using (9) the parasitic capacitance at the resonance frequency is derived as below:

$$
C_{p a r}\left(\omega_{0}\right)=\frac{\sqrt{k^{2}-1}}{\Delta f \cdot R_{\text {parp }}\left(\omega_{0}\right)}
$$

Then, the parallel inductance can be calculated at resonance frequency.

$$
L_{\text {indp }}\left(\omega_{0}\right)=\frac{1}{C_{p a r}\left(\omega_{0}\right) \cdot\left(2 \pi f_{0}\right)^{2}}
$$

These parameters, obtained from (10) and (11), should be further modified. A frequency modification needs to be done in order to obtain the frequency function of the real 
model parameters. This is presented in the following section in detail.

\section{Frequency Modification of the Parallel RLC Circuit Parameters}

Resistances and inductances depend on the frequency, where this dependency has to be considered in accurate estimation of the parameters. However, it should be noted that accurate modification of these parameters may have different complexities depending on the inductor type.

\subsection{Resistance Frequency Modification}

The AC resistance of an inductor Rac includes two parts; winding resistance $\mathrm{Rw}$ and the core equivalent resistance Rc [7-10]. For the air-core inductors as well as quite low core loss inductors (like inductors of the EMI filters), Rc is almost zero; but, iron-core losses need to be taken for Rac into account. Also, the winding resistance depends on frequency in terms of the losses due to the proximity effect and the skin effect.

The EMI filters are designed such that introducing the minimum parasitic capacitance. Thus, the single-layer single-strand is used; neglecting the proximity effect (the estimation proposal is not restricted to single-layer inductors though). To formulate the frequency-dependency, first the skin penetration depth is calculated as follows:

$$
\delta_{w}=\sqrt{\frac{\rho_{w}}{\pi \mu_{0} \mu_{r w} f}}
$$

Where $\rho w$ is resistivity of wire, $f$ is frequency, $\mu \mathrm{rw}$ is relative permeability and $\mu 0$ is absolute permeability. Having calculated the penetration depth, the resistance is modified for round and flat conductors for single-layer and multi-layer inductors.

Single-layer inductors: The coil resistance is modified according to its dc resistance (RwDC) and the conductor cross section. Assume diameter of a round wire is dcu, then the winding resistance can be expressed by:

$$
\frac{R_{w A C}}{R_{w D C}}=\frac{A_{w D C}}{A_{w A C}}=\frac{d_{c u}^{2}}{4 \delta_{w}\left(d_{c u}-\delta_{w}\right)}=k_{C o}
$$

And for a flat wire (dimensions are defined by $\mathrm{a} \times \mathrm{h}$ ) is expressed by (only the conductor cross section is needed):

$$
\frac{R_{w A C}}{R_{w D C}}=\frac{A_{w D C}}{A_{w A C}}=\frac{a \cdot h}{2 \delta_{w}\left(a+h-2 \delta_{w}\right)}=k_{C o}
$$

Multi-layer inductors: Assume $\mathrm{p}$ is the center-to-center distance between two adjacent turns, and $\mathrm{Nl}$ is the number of layers; first a coefficient $\mathrm{A}$ is calculated as below:

Then, the frequency modification is made as follows and the first term in the RHS of (16) shows the skin effect, and the second one introduces the proximity effect.

$$
\left\{\begin{array}{c}
A=\left(\frac{\pi}{4}\right)^{\frac{3}{4}} \frac{\sqrt{d_{c u}^{3}}}{\delta_{w} \sqrt{p}} \\
A=\frac{a}{\delta_{w}} \sqrt{\frac{h}{p}}
\end{array}\right.
$$

$$
\begin{aligned}
& \frac{R_{w A C}}{R_{w D C}}=A\left[\frac{e^{2 A}-e^{-2 A}+2 \sin (2 A)}{e^{2 A}+e^{-2 A}-2 \cos (2 A)}\right] \\
& +A\left[2 \frac{N_{i}^{2}-1}{3} \cdot \frac{e^{A}-e^{-A}-2 \sin (A)}{e^{A}-e^{-A}+2 \cos (A)}\right]
\end{aligned}
$$

\subsection{Inductance frequency modification}

The inductance is changing by frequency because of two features; permeability of the inductor core and the variations of magnetic field due to the skin effect and proximity effect. The skin effect influences the internal flux of the conductor. Simulations show insignificant variations due to the skin effect up to $30 \mathrm{MHz}$, which agrees with the measured results. Hence, this paper concentrates on the permeability variations that are different for different materials. For the ferrite or iron powder, permeability will not change up to a few $\mathrm{MHz}$, resulting in resonance frequencies about a few hundred $\mathrm{KHz}$ along with a bandwidth of less than one $\mathrm{MHz}$. The frequency dependency of an inductor is negligible when an air-core or a non-magnetic material core is applied. Hence, the following relationship approximately modifies the inductance, when the frequency-dependent specifications of the core are available [1].

$$
L_{\text {indp }}(\omega)=L_{\text {indp }}\left(\omega_{0}\right) \cdot \frac{\mu_{e q}\left(\omega_{0}\right)}{\mu_{e q}(\omega)}
$$

Where $\mu_{e q}$ is the equal permeability of the core. In practice, if bobbin length $\left(l_{\text {sol }}\right)$ is at least $20 \%$ less than the diameter of the core $(\mathrm{Dm})$ for a solenoid with an iron-core or silicon iron-core, the equal permeability is suggested by the following experimental relationship [1].

$$
\mu_{e q}=\frac{0.45 D_{m}+l_{s o l}}{0.45 D_{m}+0.1 \times l_{s o l}}
$$


For those inductors which have the air gaps with UI- EIEE- UU- CC cores, and the respective core and air gap lengths are $\mathrm{lc}$ and $\mathrm{lg}$, respectively, the equal permeability value may be found using the following relation.

$$
\mu_{e q}=\frac{l_{c}+l_{g}}{\frac{1}{\mu_{0}}\left(l_{g}+\frac{l_{c}}{\mu_{\text {rcore }}}\right)}
$$

Where $\mu_{0}$ is the air permeability and $\mu_{r}$ is the relative permeability of the core.

\subsection{Capacitance Frequency Modification}

Change of the parasitic capacitance of an inductor is associated with the permittivity change of the capacitor composing materials due to the frequency change. Permittivity of most materials, especially the insulating materials, remains unchanged within the range of a few of hundred MHz. Hence, insignificant change of permittivity with frequencies up to $30 \mathrm{MHz}$ has no considerable affect on the inductor parasitic capacitance.

\section{Proposed Estimation Procedure}

Since the estimated parameters depend on $\mathrm{k}$, impedance of the inductor will be calculated for each $\mathrm{k}$. The closeness criterion of the measured impedance and the estimated impedance curves can be defined by the mean root squared error (Eav):

$$
\begin{aligned}
& E_{i}=\left|Z_{i(\text { Measurement })}\right|-\left|Z_{i(\text { Estimated })}\right| \\
& E_{A v}=\sqrt{\frac{1}{N} \sum_{i=1}^{N} E_{i}^{2}}
\end{aligned}
$$

Then, $\operatorname{Eav}(\mathrm{k})$ is calculated for different $\mathrm{k} \in[1, \mathrm{~N}]$ with a tiny variation step. The optimum $\mathrm{k}$ is found for estimation when $\operatorname{Eav}(\mathrm{k})$ is minimized.

A summarized outline of the described method is as follows:

Step1. Provide the required input data: The required data to begin the estimation process are:

- the inductor's impedance magnitude vs. frequency as measured samples,

- the DC resistance of the inductor winding,

- the core permeability vs. frequency (if needed for a better accuracy).

Step2. Note down the resonance point and the resistance of the parallel model (Fig. 2) using the measured samples.
Step3. Working with the measured samples curve divide the curve into $\mathrm{N}$ regions with a resolution of $\Delta \mathrm{Z}=$ (Zmax-Zmin)/N.

Step4. Set $\mathrm{i}=1$.

Step5. Calculate $Z(i)=Z \max -i \times \Delta Z$ and calculate the corresponding bandwidth, i.e. $\Delta \omega$.

Step6. Calculate the parasitic capacitance and inductance of the parallel model at the resonance frequency (using (10) and (11)).

Step7. Calculate the modified resistance and inductance of the real model (Fig. 1) at the resonance frequency.

Step8. Revise the parameters of the real model according to (16) and (17) considering frequency-dependent characteristics.

Step9. Work out the impedance of the inductor's real model based on the estimated parameters, and compare them with the measured impedance at different frequencies.

Step 10. Find out the mean squared error between the estimation and the measurement.

Step 11. Set $i=i+1$.

Step 12. Go to step three until $i=N$.

Step 13. Determine k according to the iteration that gives the lowest error.

Step 14. The model is obtained, stop the procedure.

This procedure is verified by both simulations and experiments including extensive measurements. The results as well as some important details are presented in the following section.

\section{Experiments and Simulation}

Here the proposed estimation algorithm is assessed; six different inductors (both single-layer and multi-layer using the lacquer coated round wire) with different structures and cores were implemented to make different tests and measurements. These practical experiments are as follows:

\subsection{Toroid Inductor with Iron Powder Core}

Here, a toroidal inductor was implemented (Fig. 5) on an iron powder core produced by Micrometals Company of type T300-26D. The external diameter of the core is $77.2 \mathrm{~mm}$, the internal diameter $49 \mathrm{~mm}$ and the core height consists of two parts of identical length each $25.4 \mathrm{~mm}$. The winding includes 84 turns of lacquer coated wire with $\mathrm{dcu}=1.6 \mathrm{~mm}$, and distances of the turns at the core perimeter were equally formed. Figure 4 depicts the frequency-dependent variations of the permeability of the core that was provided by the manufacturing company as Fig. 4. 
Using a precise LRC meter $81010 \mathrm{GW}$-INSTEK analyzer, the impedance magnitude of this toroidal inductor was measured as shown in Fig. 6.

The resonance frequency is around $500 \mathrm{KHz}$. Then, using the suggested estimation algorithm, the parameters of the toroidal inductor were estimated. The minimum $\operatorname{Eav}(\mathrm{k})$ was obtained for $\mathrm{k}=1.096$ (or $-0.7991 \mathrm{~dB}$ ). The parameters of a real inductor (see Fig. 1) for the resistance and inductance were estimated as shown in Figs. 7-9.

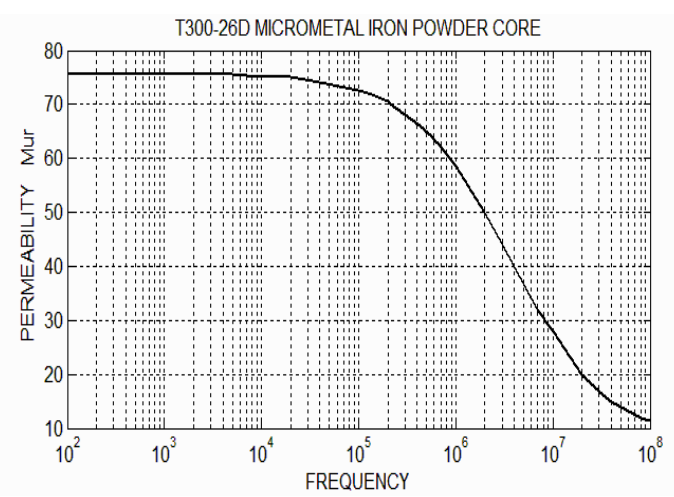

Fig. 4. Permeability changes based on frequency for the T300-26D iron powder core for inductor a

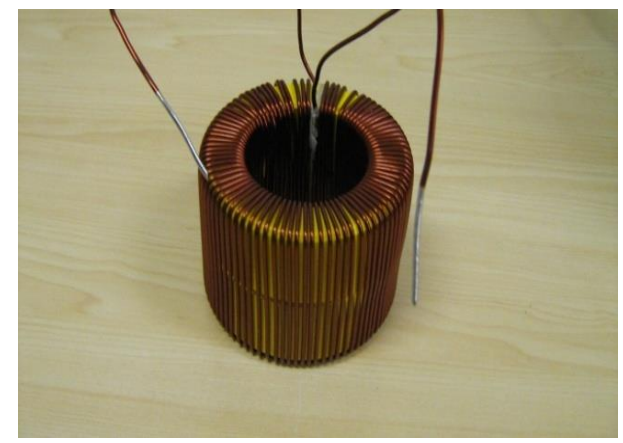

Fig. 5. Inductor a: toroidal inductor with an iron powder core of type T300-26D produced by Micrometals company

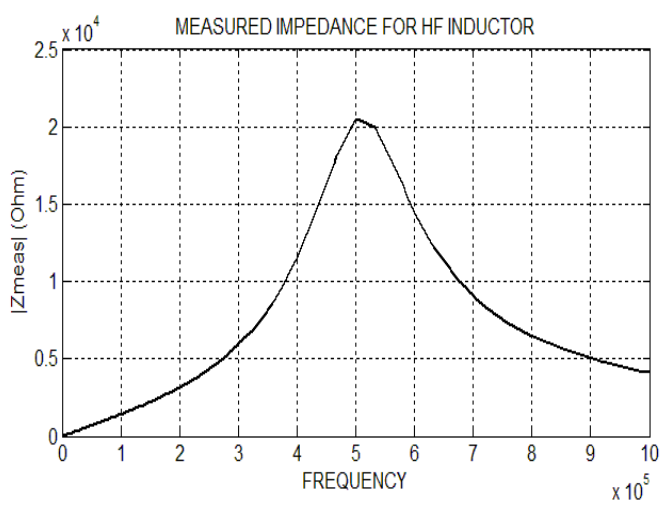

Fig. 6. Drawing the measured impedance at MATLAB for inductor a

Calculations also give a capacitance of about $47.048 \mathrm{pF}$ for Cpar. Using the estimated values, the impedance magnitudes were worked out and compared with the measured impedances shown in Fig. 10.

The dotted curve presents the estimated impedances in comparison with the solid curve for the measured impedances, where the difference between these two curves is shown in Fig. 11. This error at the resonance frequency is zero, while it becomes bigger by distancing from the resonance frequency.

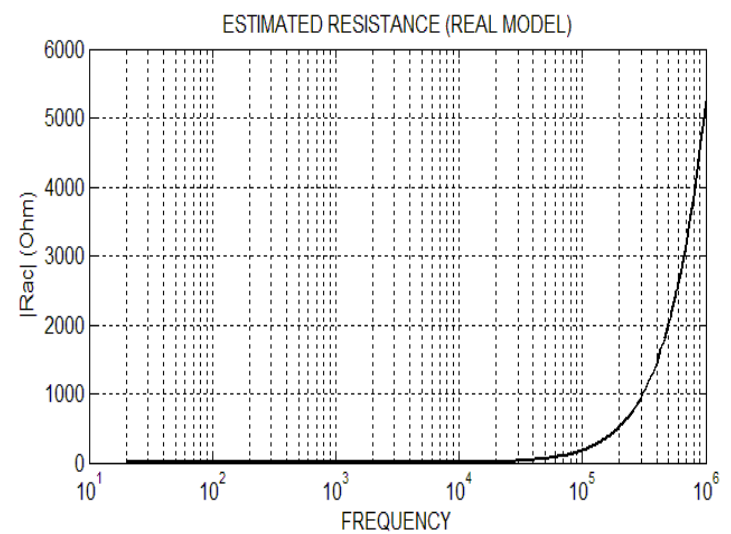

Fig. 7. Estimated value for the real equal circuit resistance for inductor a

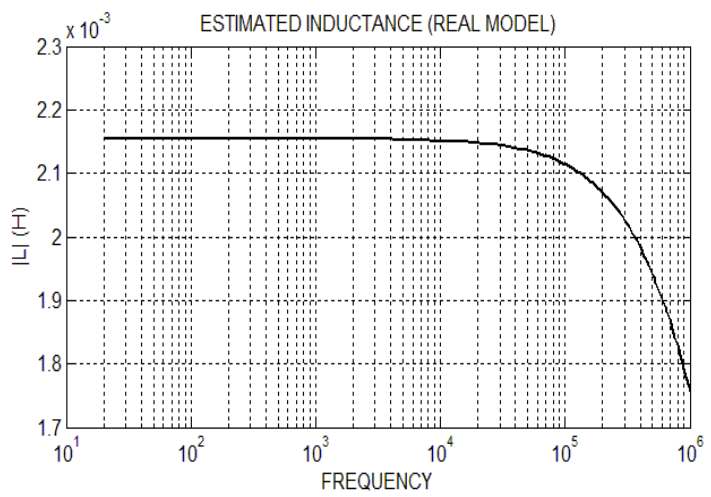

Fig. 8. Estimated value for the real equal circuit inductance for inductor a

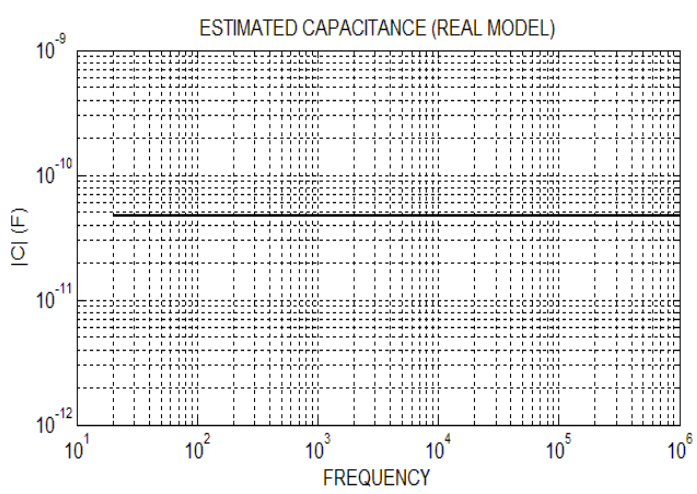

Fig. 9. Estimated value for the real equal circuit parasitic capacitance for inductor a 


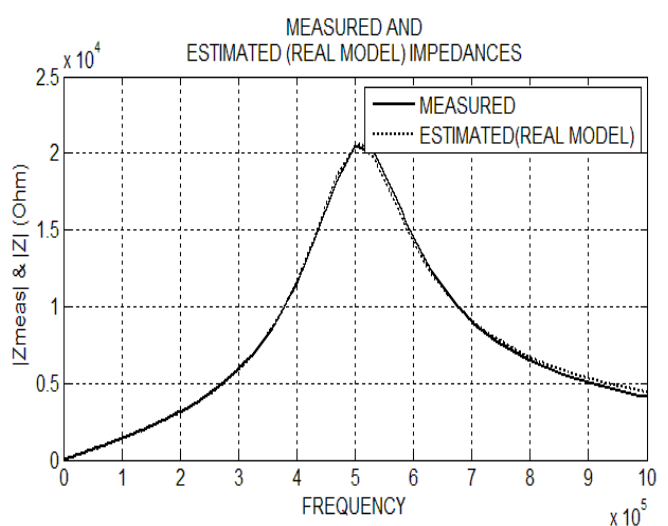

Fig. 10. Comparison of the measured and estimated impedance values for inductor a

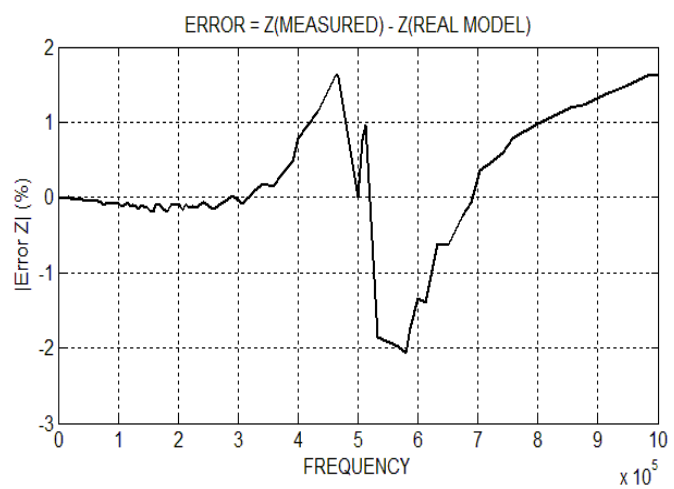

Fig. 11. Measured and estimated impedances error specification for inductor a

In brief, the root mean squared error was calculated as $0.0702 \%$ for the toroidal inductor with iron powder core.

\subsection{Toroid inductor with ferrite core}

The second example (Fig. 12) describes an implemented toroidal inductor that uses a ferrite core (the core produced by SAMWAH Company of type OR66x38_30H). The external diameter of the core is $66 \mathrm{~mm}$, the internal diameter $38.6 \mathrm{~mm}$ and the core height of $29.4 \mathrm{~mm}$. The winding includes 29 turns of lacquer coated wire with $\mathrm{dcu}=1.88 \mathrm{~mm}$, and distances of the turns at the core perimeter were equally formed. The core material is SM-23T, which Fig. 13 presents the frequency-dependent permeability variations for this core provided by the manufacturing company. Measurements show impedance of about $4.35 \mathrm{k} \Omega$ at the resonance frequency around $100 \mathrm{KHz}$ (see Fig. 14). The estimated parameters were obtained for $\mathrm{k}=1.644$ (or -4.3160 $\mathrm{dB})$ with the root mean squared error of $1.4291 \%$. The parasitic capacitance of this inductor was also worked out about 639.31 pF (see Figs. 15-19).

\subsection{Solenoid Inductor with Fiber core with I shape}

Then, a solenoid inductor (Fig.20) was examined, having

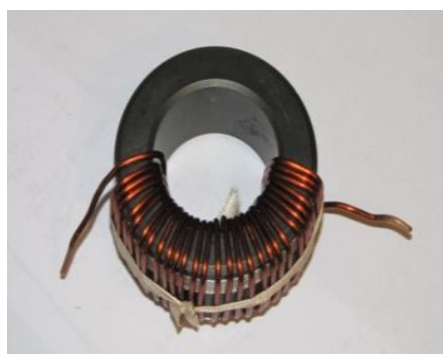

Fig. 12. Inductor b: toroidal inductor with a ferrite core of type OR66x38_30H produced SAMWAH Company

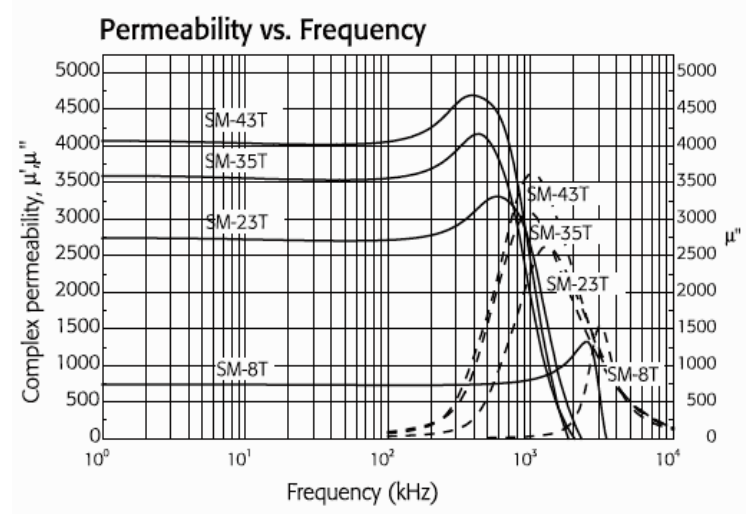

Fig. 13. Permeability changes based on the frequency for the ferrite core for inductor $b$

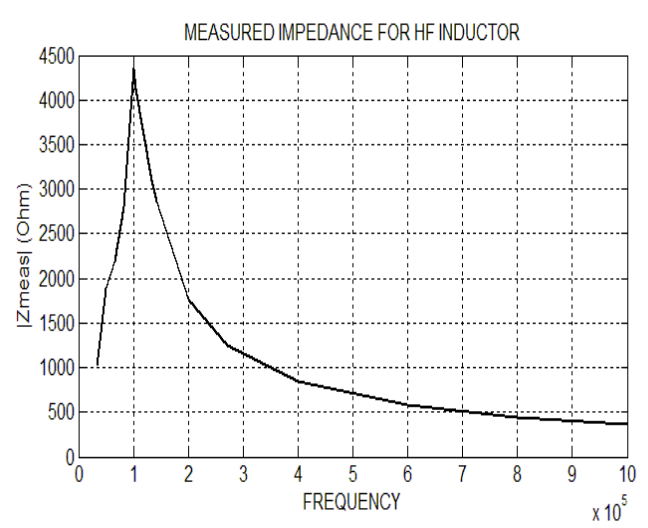

Fig. 14. Drawing the impedance measured in MATLAB for Inductor $\mathrm{b}$

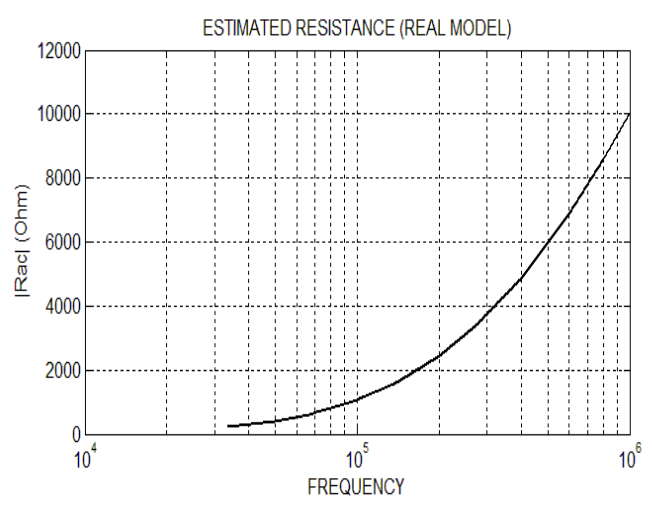

Fig. 15. Estimated value for the real equal circuit resistance for inductor $b$ 


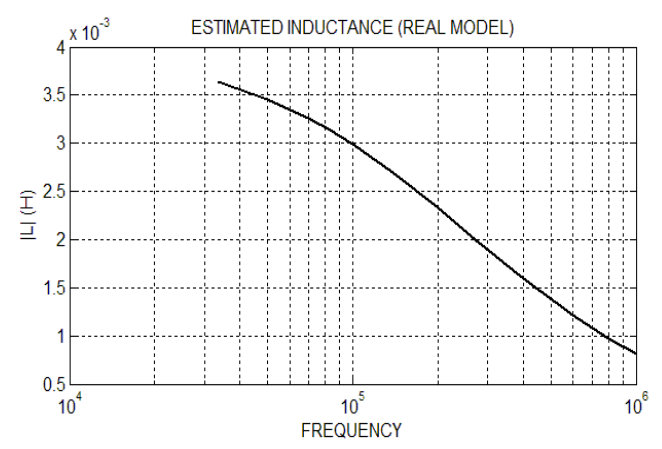

Fig. 16. Estimated value for the real equal circuit ductance for inductor $b$

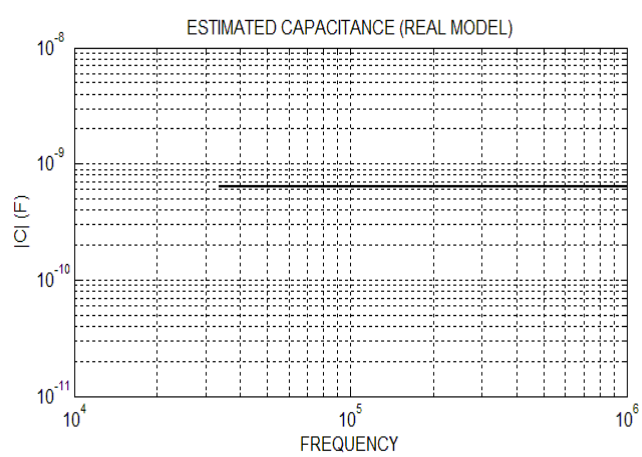

Fig. 17. Estimated value for the real equal circuit parasitic capacitance for inductor $b$

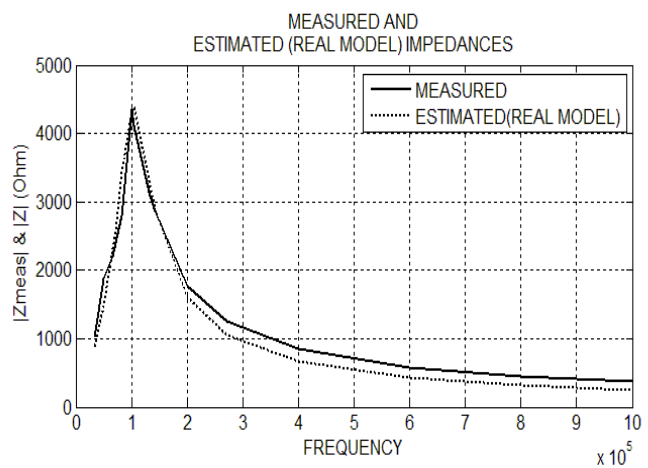

Fig. 18. Comparison of the measured and estimated impedance values for inductor $b$

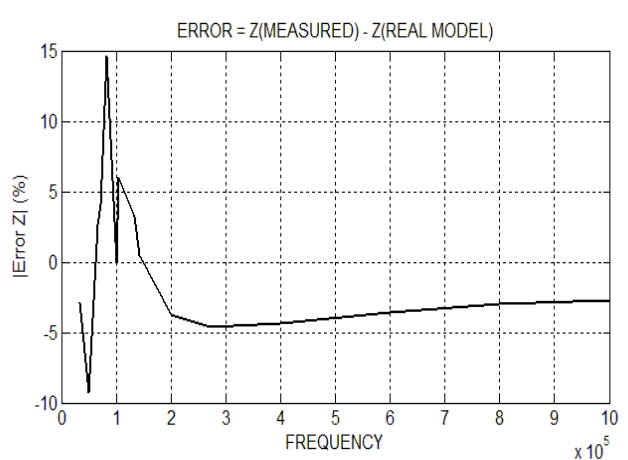

Fig. 19. Measured and estimated impedances error specification for inductor $b$

an I- shape fiber core with cross sectional area of 5.2 $27.4 \mathrm{~mm} 2$. The core length is $70 \mathrm{~mm}$, and includes 20 turns of lacquer coated wire with dcu $0.4 \mathrm{~mm}$. Measurements show impedance of about $15.1 \mathrm{k} \Omega$ at the resonance frequency around $46 \mathrm{MHz}$ (see Fig. 21). The estimated parameters were obtained for $\mathrm{k}=1.412$ (or $-3 \mathrm{~dB}$ ) with the mean root squared error of $0.3159 \%$. The parasitic capacitance of this inductor was also worked out about 2.3056 pF (see Figs. 22-26).

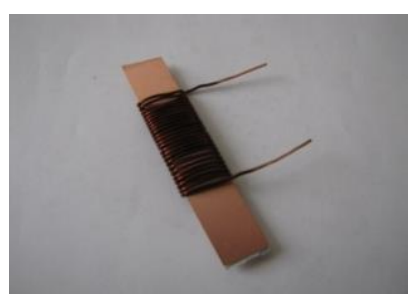

Fig. 20. Inductor c with I- shape fiber core

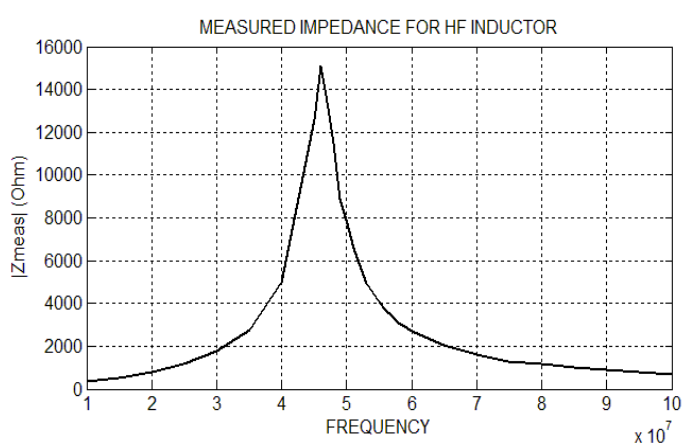

Fig. 21. Drawing the impedance measured in MATLAB for inductor $\mathrm{c}$

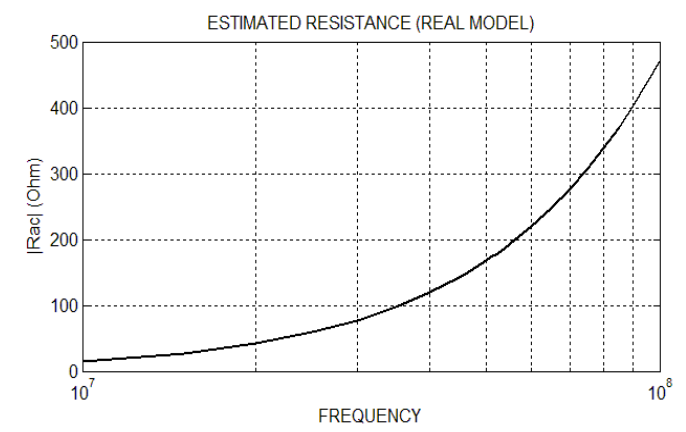

Fig. 22. Estimated value for the real equal circuit resistance for inductor $\mathrm{c}$

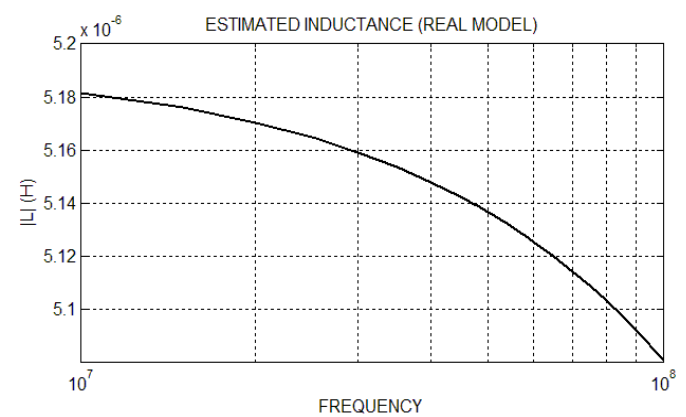

Fig. 23. Estimated value for the real equal circuit inductance for inductor $\mathrm{c}$ 


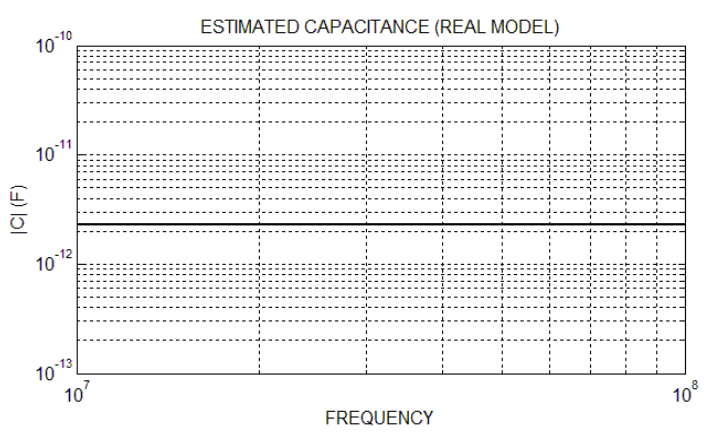

Fig. 24. Estimated value for the real equal circuit parasitic capacitance for inductor $\mathrm{c}$

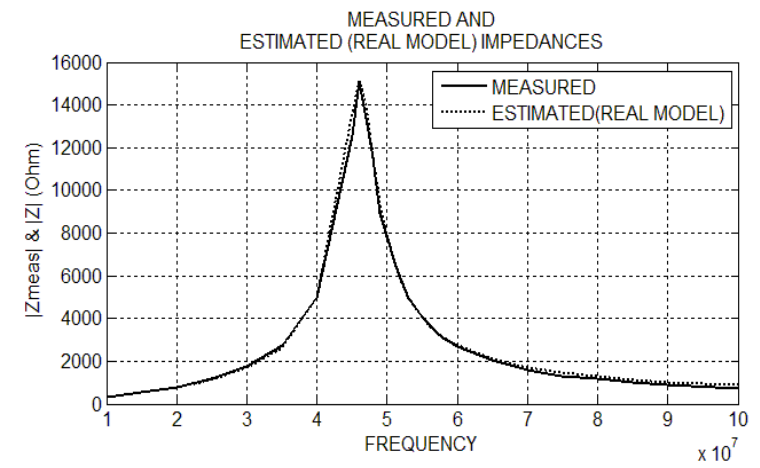

Fig. 25. Comparison of the measured and estimated impedance values for inductor $\mathrm{c}$

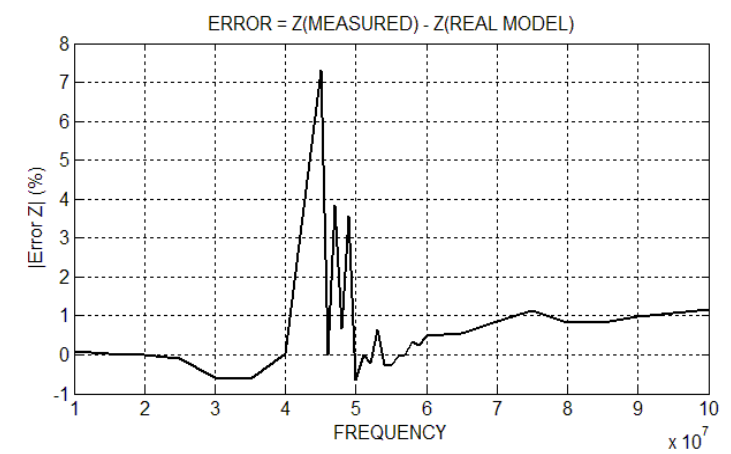

Fig. 26. Measured and estimated impedances error specification for inductor $\mathrm{c}$

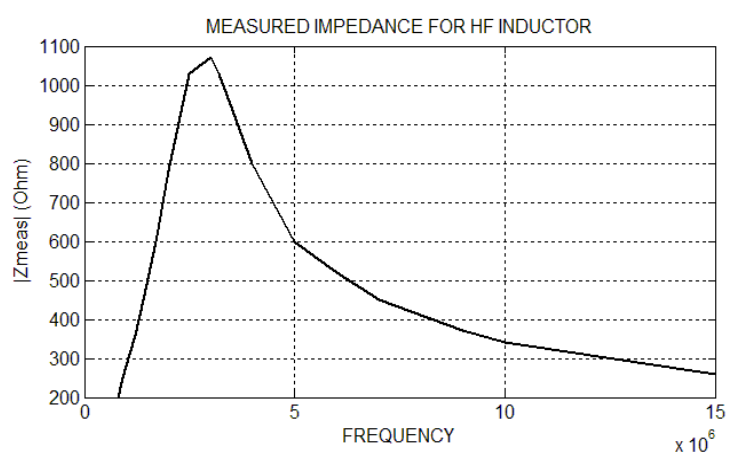

Fig. 27. Drawing the impedance measured in MATLAB for inductor $\mathrm{d}$

\subsection{Solenoid Inductor with Ferrite core with I shape}

Additionally, a solenoid inductor was examined, having an I-shape ferrite core with cross sectional area of $8.315 .5 \mathrm{~mm} 2$. The core length is $70 \mathrm{~mm}$ and includes 20 turns of lacquer coated wire with dcu $0.4 \mathrm{~mm}$. Measurements show impedance of about $1.07 \mathrm{k} \Omega$ at the resonance frequency around $3 \mathrm{MHz}$ (see Fig. 28). The estimated parameters were obtained for $\mathrm{k}=1.954$ (or -5.8192 $\mathrm{dB})$ with the mean root squared error of $1.4827 \%$. The parasitic capacitance of this inductor was also worked out about 65.933 pF (see Figs. 28-32).

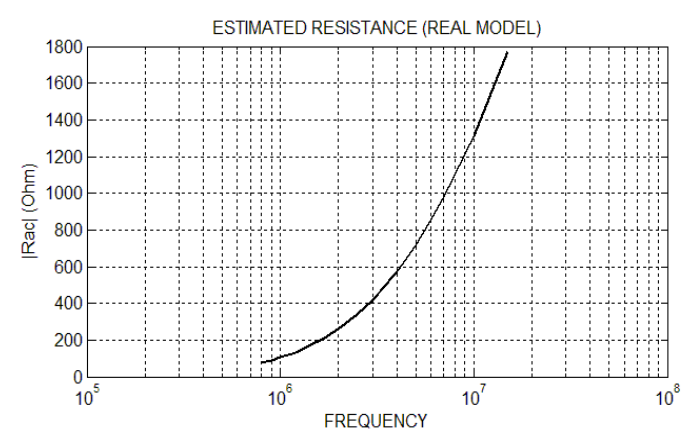

Fig. 28. Estimated value for the real equal circuit resistance for inductor $\mathrm{d}$

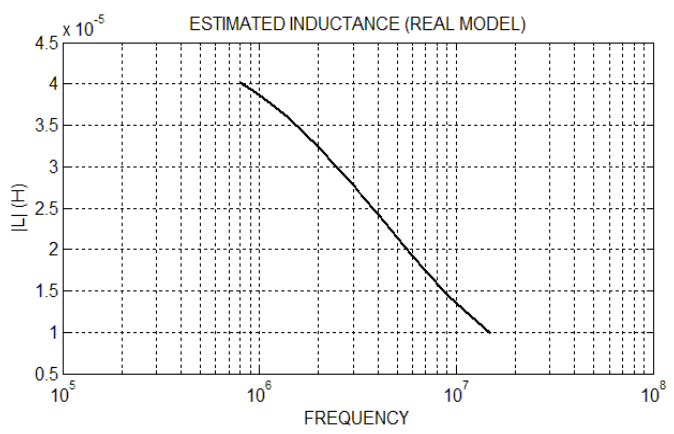

Fig. 29. Estimated value for the real equal circuit inductance for inductor $\mathrm{d}$

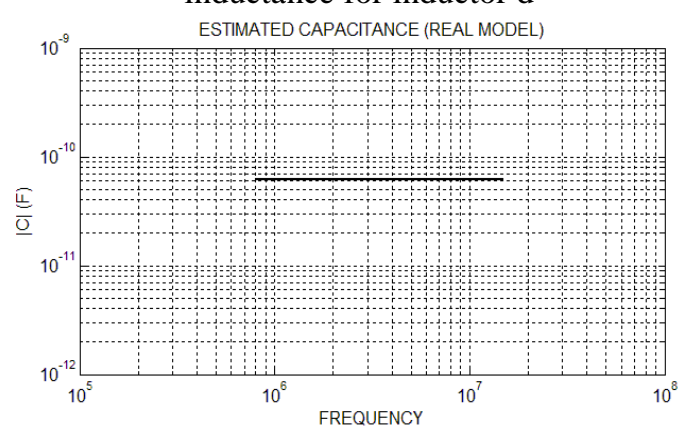

Fig. 30. Estimated value for the real equal circuit parasitic capacitance for inductor $\mathrm{d}$

The fifth example examines an implemented solenoid inductor (Fig. 33) that uses a ferrite core (the core produced by SAMWAH Company of type EER3540S). The air-gaped core has a central column having a circular cross section area with a diameter of $11.2 \mathrm{~mm}$. Specifications of the 
air-gap as well as the dimensions of the core are listed in Tables $1 \& 2$ as well as Fig. 34. The total width of the core is $35 \mathrm{~mm}$ with a thickness of $11.2 \mathrm{~mm}$, total height of 42 $\mathrm{mm}$ and the air-gap length for the central column is $1 \mathrm{~mm}$. The winding includes 36 turns of lacquer coated wire with $\mathrm{dcu}=0.6 \mathrm{~mm}$, and the turns are equally distributed over the core perimeter.

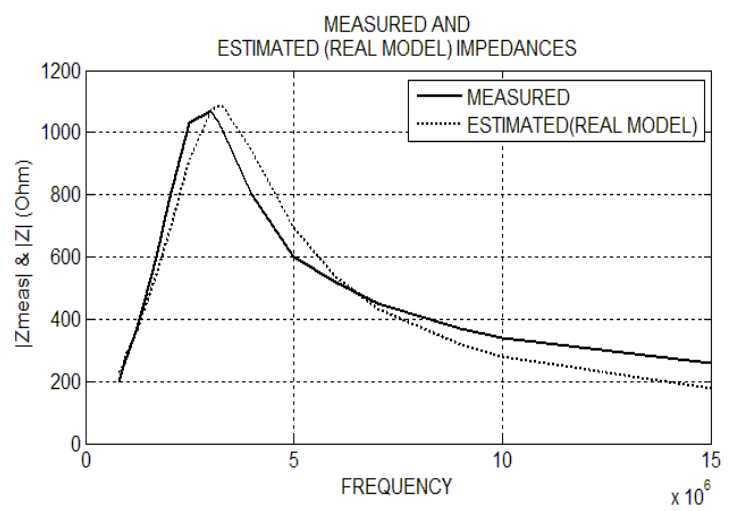

Fig. 31. Comparison of the measured and estimated impedance values for inductor $\mathrm{d}$

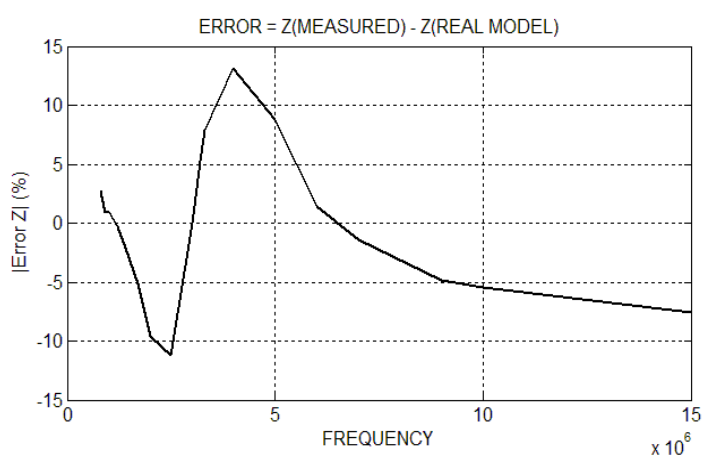

Fig. 32. Measured and estimated impedances error specification for inductor $\mathrm{d}$

\subsection{Solenoid Inductor with EE-shape (circular central column) Ferrite core}

Measurements show impedance of about $31 \mathrm{k} \Omega$ at the resonance frequency around 4.6 $\mathrm{MHz}$ (see Fig. 36). The estimated parameters were obtained for $\mathrm{k}=1.193$ (or -1.5356 $\mathrm{dB})$ with the root mean squared error of $0.3546 \%$. The parasitic capacitance of this inductor was also worked out about 42.2887 PF (see Figs. 37-41).

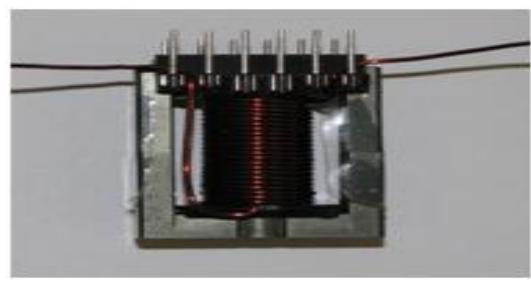

Fig. 33. Inductor e
Table 1: Specifications of the core

\begin{tabular}{|c|c|c|c|}
\hline $\begin{array}{c}\text { Mate } \\
\text { rial }\end{array}$ & $\begin{array}{c}\mathrm{A}_{\mathrm{L}} \text { Value } \\
\left(\mathrm{nH} / \mathrm{N}^{2}\right)\end{array}$ & $\mu_{\mathrm{e}}$ & $\begin{array}{c}\text { Air gap } \\
(\mathrm{mm})\end{array}$ \\
\hline PL-7 & $170 \sim 2600$ & $110 \sim$ & $0.0 \sim 1.00$ \\
\hline
\end{tabular}

\begin{tabular}{|c|c|c|c|}
\hline Parameter & $\begin{array}{c}\text { Symbo } \\
1\end{array}$ & Value & Unit \\
\hline Core constant & $\mathrm{Cl}$ & 0.813 & $\mathrm{~mm}^{-1}$ \\
\hline $\begin{array}{c}\text { Effective path } \\
\text { length }\end{array}$ & $\mathrm{Le}$ & 88.6 & $\mathrm{~mm}$ \\
\hline Effective area & $\mathrm{Ae}$ & 109.0 & $\mathrm{~mm}^{2}$ \\
\hline Effective volume & $\mathrm{Ve}$ & 9657 & $\mathrm{~mm}^{3}$ \\
\hline Center leg area & $\mathrm{Ac}$ & 100.3 & $\mathrm{~mm}^{2}$ \\
\hline Winding area & $\mathrm{Aw}$ & 219.0 & $\mathrm{~mm}^{2}$ \\
\hline Weight of set & $\mathrm{W}$ & 50 & $\mathrm{gr}$ \\
\hline
\end{tabular}

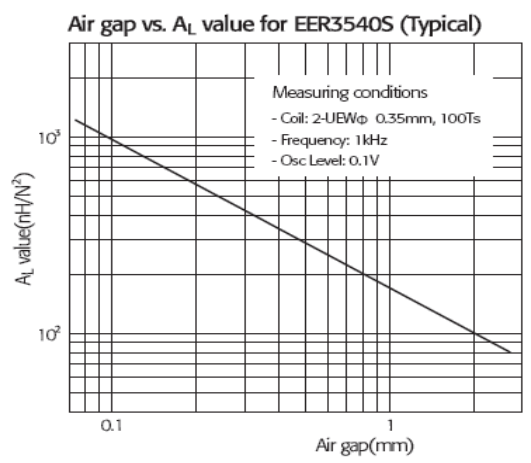

Fig. 34. AL value changes Based on the air gap for inductor

Table 2: Specifications of the PL-7 material

\begin{tabular}{|c|c|c|c|l|}
\hline & Symbol & Unit & Temperature ${ }^{\circ} \mathrm{C}$ & Value \\
\hline Initial Permeability & $\mu_{\text {iac }}$ & & & 2400 \\
\hline $\begin{array}{l}\text { Core loss (100kHz, } \\
\text { 200mT) }\end{array}$ & $\mathrm{P}_{\mathrm{CV}}$ & \multirow{2}{*}{$\mathrm{Kw} / \mathrm{m}^{3}$} & 23 & 650 \\
\cline { 4 - 5 } & & & 100 & 450 \\
\hline $\begin{array}{c}\text { Saturation flux } \\
\text { density (1194A/m) }\end{array}$ & $\mathrm{B}_{\mathrm{S}}$ & $\mathrm{mT}$ & 23 & 490 \\
\hline Remanence & $\mathrm{B}_{\mathrm{r}}$ & $\mathrm{mT}$ & 100 & 380 \\
\hline Coercivity & $\mathrm{H}_{\mathrm{C}}$ & $\mathrm{A} / \mathrm{m}$ & 23 & 150 \\
\hline Curie temperature & $\mathrm{T}_{\mathrm{C}}$ & ${ }^{\circ} \mathrm{C}$ & 23 & 12 \\
\hline Density & $\mathrm{d}$ & $\mathrm{Kg} / \mathrm{m}^{3}$ & & $>220$ \\
\hline Resistivity & $\rho$ & $\Omega . \mathrm{m}$ & & 4850 \\
\hline
\end{tabular}

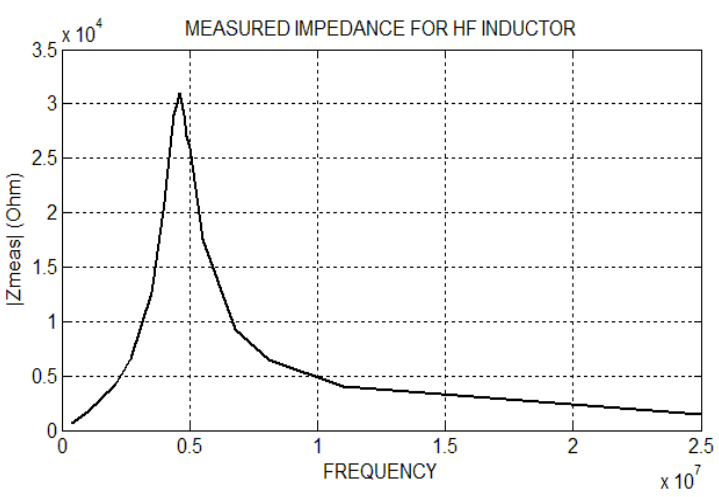

Fig.36. Drawing the impedance measured in MATLAB for inductor e 


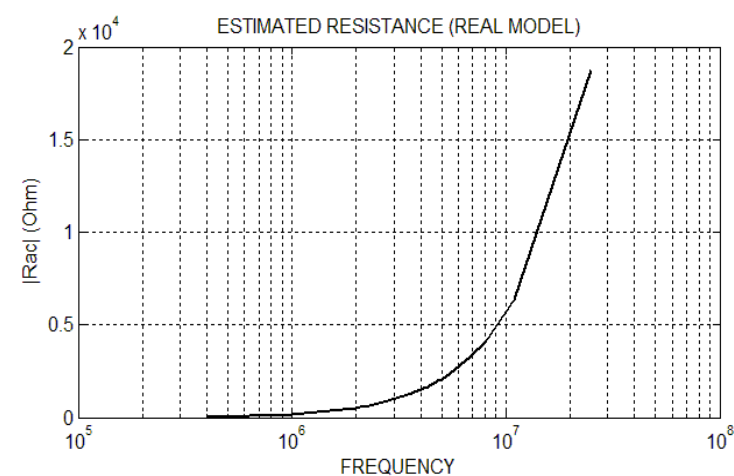

Fig. 37 Estimated value for the real equal circuit resistance for inductor e

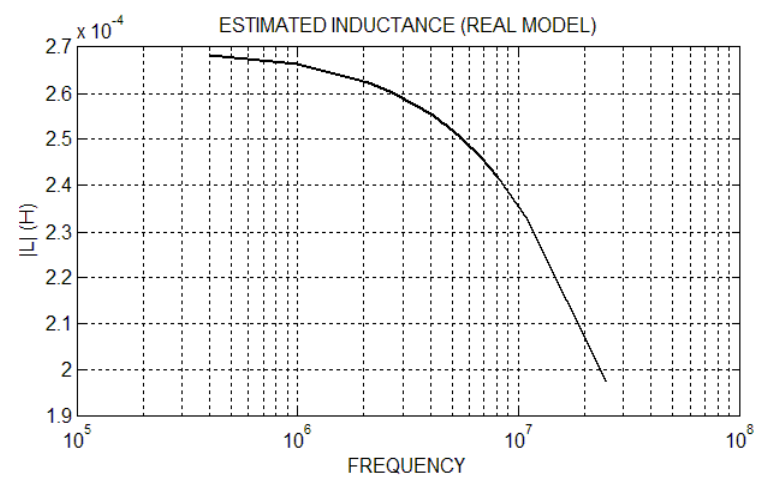

Fig. 38 Estimated value for the real equal circuit inductance for inductor e

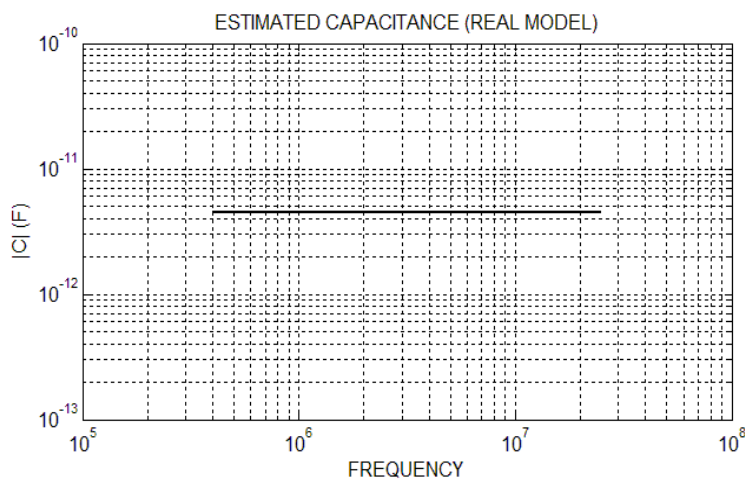

Fig. 39 Estimated value for the real equal circuit parasitic capacitance for inductor e

The next example looks at an implemented solenoid inductor (Fig. 42) having a circular winding with diameter of dcore $=40 \mathrm{~mm}$. The winding length is $120 \mathrm{~mm}$, includes 96 turns (at 3 layers) of lacquer coated wire with dcu $=1.71 \mathrm{~mm}$. The layers are separated by insulation sheets each having $1 \mathrm{~mm}$ thickness. The turn to turn distance is $3.6 \mathrm{~mm}$ and the turns are equally distributed over the core perimeter. Measurements show impedance of about $36 \mathrm{k} \Omega$ at the resonance frequency around $1.004 \mathrm{MHz}$ (see Fig. 43). The estimated parameters were obtained for $\mathrm{k}=1.412$ (or -3 $\mathrm{dB})$ with the root mean squared error of $0.2104 \%$. The parasitic capacitance and the inductance of this inductor were also worked out about $117.48 \mathrm{pF}$ and $213.6 \mu \mathrm{H}$ respectively (see Figs. 44-47).

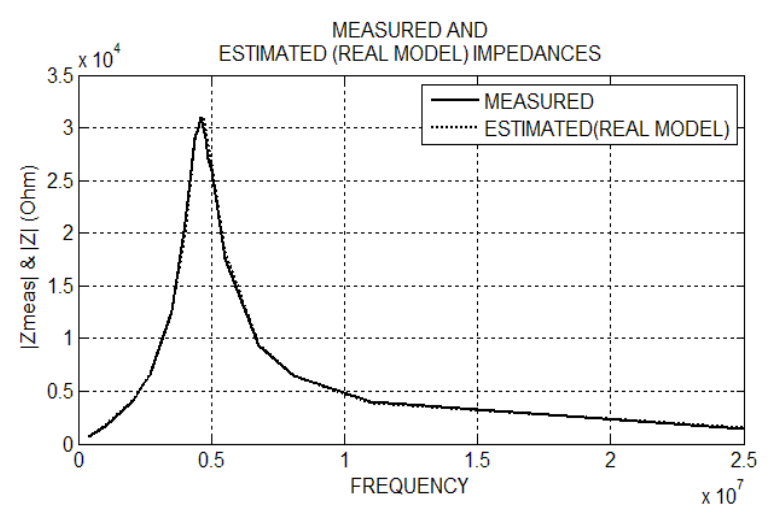

Fig. 40. Comparison of the measured and estimated impedance values for inductor e

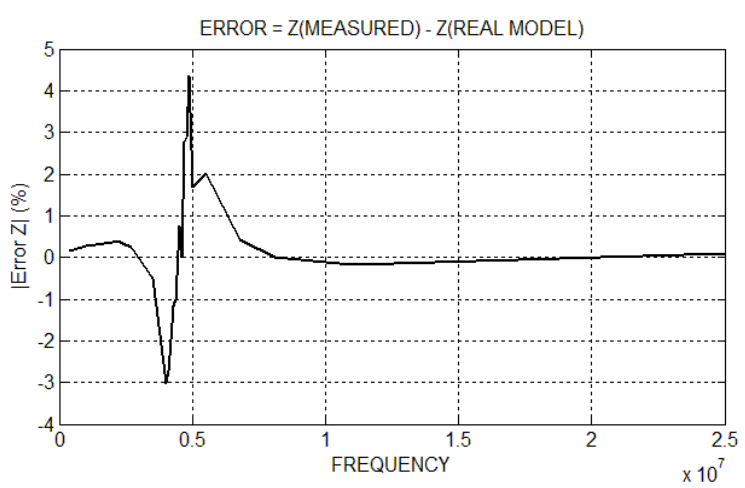

Fig. 41. Measured and estimated impedances error specification for inductor e

\subsection{Solenoid Inductor -Air core, Three layers}

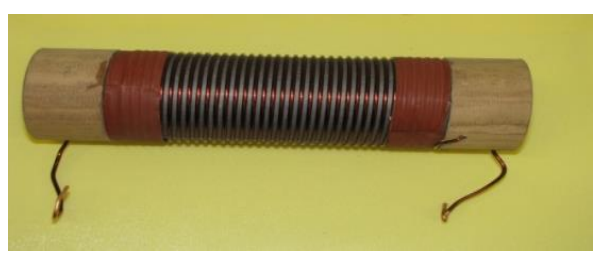

Fig. 42. Inductor $\mathrm{f}$

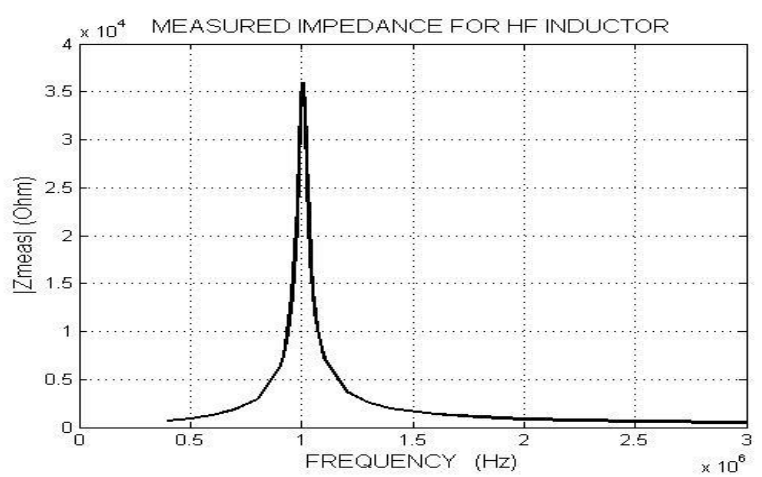

Fig. 43. Drawing the impedance measured in MATLAB for inductor $\mathrm{f}$ 


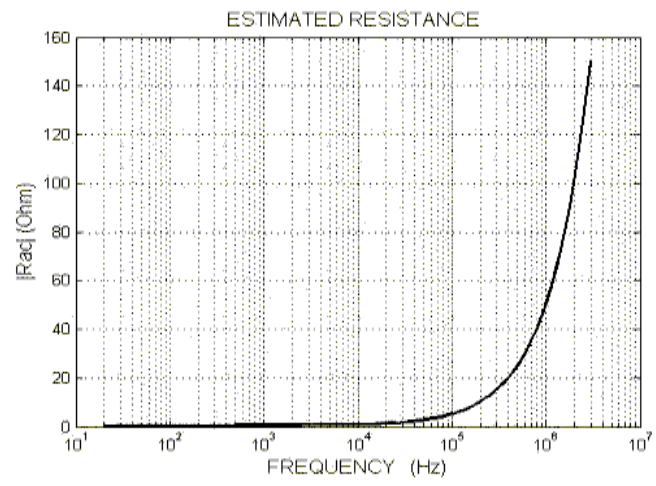

Fig. 44. Estimated value for the real equal circuit resistance for inductor $\mathrm{f}$

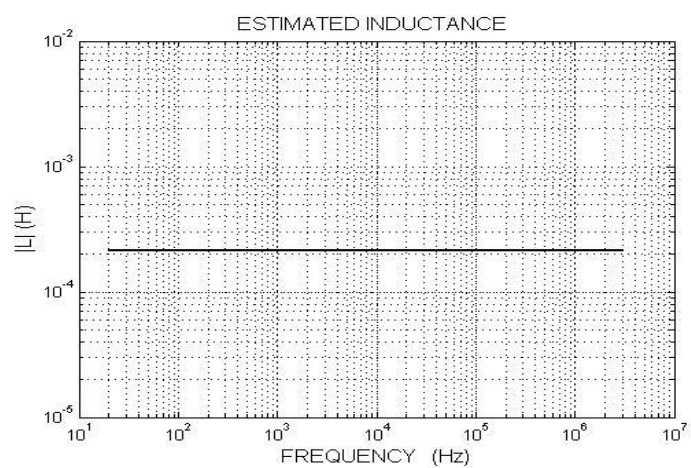

Fig. 45. Estimated value for the real equal circuit inductance for inductor $\mathrm{f}$

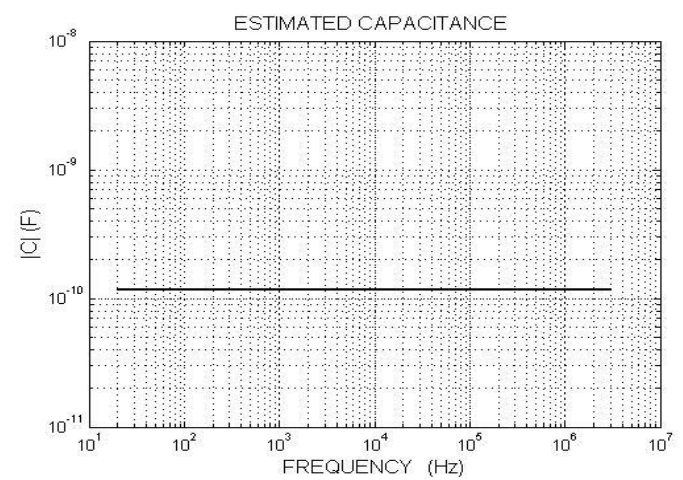

Fig. 46. Estimated value for the real equal circuit parasitic capacitance for inductor $\mathrm{f}$

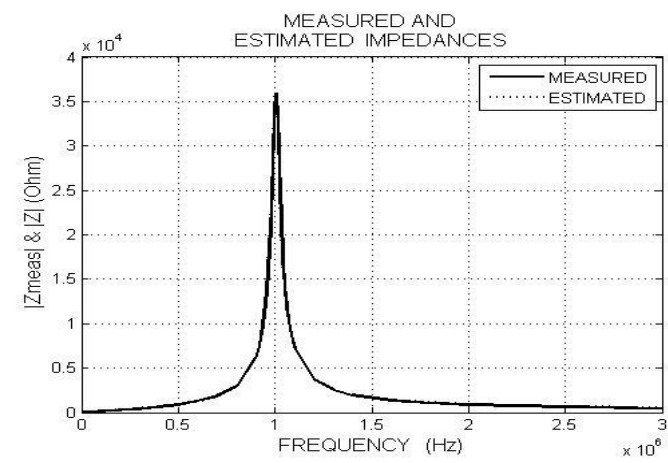

Fig. 47.Comparison of the measured and estimated impedance values for inductor $\mathrm{f}$
Table 3: The results of the presented method

\begin{tabular}{|c|c|c|c|c|c|}
\hline $\begin{array}{l}\mathrm{N} \\
\mathrm{o}\end{array}$ & Core Type & $\begin{array}{l}\text { Winding } \\
\text { Type }\end{array}$ & $\begin{array}{l}\text { Optimum } \\
\mathbf{K d B}\end{array}$ & $\begin{array}{l}\text { Error } \\
\text { Criteria } \\
\text { Eav\% }\end{array}$ & $\begin{array}{l}\text { Estimate } \\
\mathrm{d} \mathrm{C}_{p a r} \mathbf{P F}\end{array}$ \\
\hline $\mathbf{a}$ & $\begin{array}{c}\text { Iron Powder- } \\
\text { Toroidal } \\
\text { T300-26D } \\
\end{array}$ & $\begin{array}{c}\text { 1-Layer } \\
84 \text { Turns } \\
1.6^{\mathrm{mm}} \\
\end{array}$ & -0.7991 & 0.0702 & 47.048 \\
\hline b & $\begin{array}{c}\text { Ferrite - } \\
\text { Toroid } \\
\text { OR66-38-30 } \\
\text { H } \\
\end{array}$ & $\begin{array}{c}\text { 1-Layer } \\
29 \text { Turns } \\
1.88^{\mathrm{mm}}\end{array}$ & -4.3160 & 1.4291 & 639.31 \\
\hline c & $\begin{array}{l}\text { Air core } \\
\text { solenoid }\end{array}$ & $\begin{array}{c}\text { 1-Layer } \\
20 \text { Turns } \\
0.4 \\
\end{array}$ & -3 & 0.3159 & 2.3056 \\
\hline d & $\begin{array}{c}\text { Ferrite - } \\
\text { Solenoid } \\
\text { I shape }\end{array}$ & $\begin{array}{c}\text { 1-Layer } \\
20 \text { Turns } \\
0.4^{\mathrm{mm}}\end{array}$ & -5.8192 & 1.4827 & 65.933 \\
\hline e & $\begin{array}{c}\text { EE-Ferrite - } \\
\text { EER3540S } \\
\text { Air gap } 1^{\mathrm{mm}} \\
\text { Circular } \\
\text { solenoid }\end{array}$ & $\begin{array}{c}\text { 1-Layer } \\
36 \text { Turns } \\
0.6^{\mathrm{mm}}\end{array}$ & -1.5356 & 0.3546 & 4.2887 \\
\hline f & $\begin{array}{l}\text { Air core } \\
\text { solenoid }\end{array}$ & $\begin{array}{c}\text { 3-Layer } \\
3 * 32= \\
96 \text { Turns } \\
1.71^{\mathrm{mm}}\end{array}$ & -3 & 0.2104 & 117.48 \\
\hline
\end{tabular}

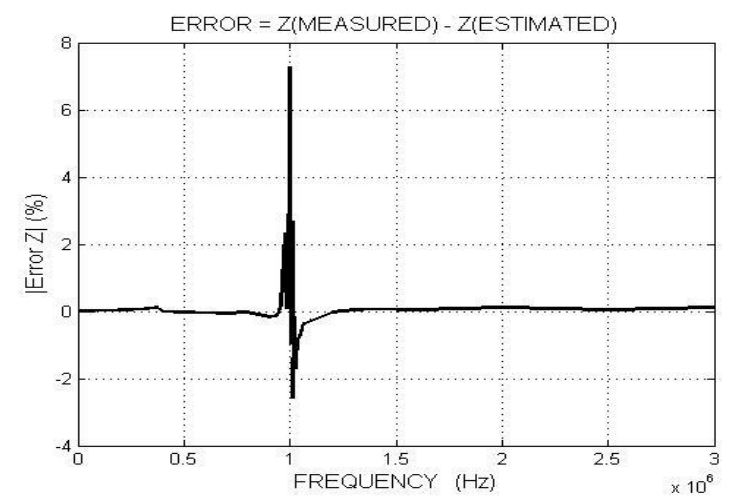

Fig. 48. Measured and estimate impedances error specification for inductor $\mathrm{f}$

In conclusion, the results of the presented method may be given with respect to the Table 3 .

\section{Conclusion}

A new method was presented to estimate the parasitic capacitance. Application of this method requires impedance frequency information in a certain bandwidth around the resonance point. This task is applicable using an impedance analyzer having proper frequency range.

Such method was performed for 6 different inductors with different cores. In this phase, all the finished inductors had single-layer formation. The core types were chosen from the air, ferrite and iron powder and in the solenoid and toroid inductor formats. Notwithstanding the approximated regulation for the resistance and inductance of the inductors frequency modification, was applied, but the presented 
results and comparison of the experimental and estimation results indicate the effectiveness of the proposed method. The maximum value of the calculated error square average in these inspections is about $1.4827 \%$. The primary presumption regarding error existence is based on inductor resistance and inductance frequency modification. Such matter may be inspected in the future. However, the impedance measurement accuracy and curve shape may also affect the error value. The observations in simulations and comparison of the same with the measured results indicate that the effect of the resistance frequency, for the inspected inductors and in case of non-modification of the inductance frequency will not change the results undesirably.

\section{APPENDIX A: PROVING THE EQUATIONS}

Here it is shown the proof of various relationships in the paper.

\section{A.1: Proving (1) and (2)}

The two RL branches in Figs. 1 and 2 are equivalent, hence, introducing identical branch impedances as follows:

$$
\begin{aligned}
& R_{\text {par }}+j \omega L_{\text {ind }}=R_{\text {parp }} P j \omega L_{\text {indp }} \\
& =\frac{R_{\text {parp }} \omega^{2} L_{\text {indp }}^{2}}{R_{\text {parp }}^{2}+\omega^{2} L_{\text {indp }}^{2}}+j \frac{R_{\text {parp }}^{2} L_{\text {indp }}}{R_{\text {parp }}^{2}+\omega^{2} L_{\text {indp }}^{2}}
\end{aligned}
$$

Separating real and imaginary parts of (A.1) results in the desired (1) and (2).

A.2: Proving (3) and (4)

Similarly, the two equivalent branches in Figs. 1 and 2 present identical admittances as below:

Separating real and imaginary parts of (A-2) result in the desired (3) and (4).

A.3: Proving (6)

$$
\begin{aligned}
& \frac{1}{R_{\text {parp }}}-j \frac{1}{\omega L_{\text {indp }}}=\frac{1}{R_{p a r}+j \omega L_{\text {ind }}}=\frac{R_{p a r}-j \omega L_{\text {ind }}}{R_{p a r}^{2}+\omega^{2} L_{\text {ind }}^{2}} \\
& =\frac{R_{p a r}}{R_{p a r}^{2}+\omega^{2} L_{\text {ind }}^{2}}-j \frac{\omega L_{\text {ind }}}{R_{p a r}^{2}+\omega^{2} L_{\text {ind }}^{2}}
\end{aligned}
$$

The impedance of parallel model is as below

$$
\mathrm{Z}(\omega)=\frac{\mathrm{R}_{\text {parp }}}{1+\mathrm{j} \mathrm{R}_{\text {parp }}\left[\omega \mathrm{C}_{\text {par }}-\frac{1}{\omega \mathrm{L}_{\text {indp }}}\right]}
$$

Combining the two relationships $\mathrm{Q}=\omega_{0} \mathrm{R}_{\text {parp }} \mathrm{C}_{\text {par }}$ and $\omega_{0}^{2} L_{\text {indp }} C_{\text {par }}=1$ in (A-3) gives

$$
Z(\omega)=\frac{R_{\text {parp }}}{1+j Q\left(\frac{\omega}{\omega_{0}}-\frac{\omega_{0}}{\omega}\right)}
$$

Where the magnitude of this impedance is

$$
|Z(\omega)|=\frac{R_{\text {parp }}}{\left[1+Q^{2}\left(\frac{\omega}{\omega_{0}}-\frac{\omega_{0}}{\omega}\right)^{2}\right]^{0.5}}
$$

Normalization of the impedance in (A-5) by Zmax=Rparp introduces the following per unit impedance that was given in (6):

$$
\left|Z_{P U}(\omega)\right|=\frac{|Z(\omega)|}{Z_{\max }=R_{\text {parp }}}=\frac{1}{\left[1+Q^{2}\left(\frac{\omega}{\omega_{0}}-\frac{\omega_{0}}{\omega}\right)^{2}\right]^{0.5}}
$$

\section{A.4: Proving (8)}

While (6) is solved for $\left|Z_{P U}(\omega)\right|=1 / k$, simplification can be applied to (7) by extending a binomial approximation for $\sqrt{1+x}$ as below:

$$
\sqrt{1+x}=1+\frac{X}{2}-\frac{X^{2}}{8}+\frac{X^{3}}{16}-\frac{5 X^{4}}{128}+\ldots
$$

If $\mathrm{X}<<1$, then $\sqrt{1+x}$ approaches to one. Hence, since $\mathrm{k} 2-1<<4 \mathrm{Q} 2,(7)$ is approximated as follows to obtain (8):

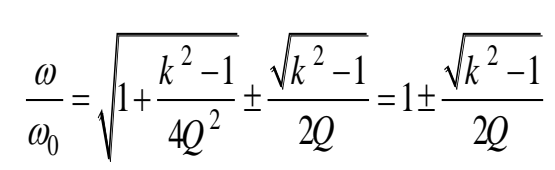




\section{Nomenclature}

\begin{tabular}{|c|l|}
\hline$A_{w D C}, A_{w A C}$ & Net cross section of wire in both DC/AC \\
\hline$C_{p a r}$ & Parasitic capacitance for real model \\
\hline$d_{c u}$ & Diameter of wire \\
\hline$H$ & Transfer function \\
\hline$K$ & Amount of attenuation \\
\hline$L_{i n d}, L_{i n d p}$ & Main inductance for real / parallel model \\
\hline$p$ & $\begin{array}{l}\text { Center-to-center distance between two } \\
\text { adjacent turns }\end{array}$ \\
\hline$Q$ & Quality factor \\
\hline$R_{p a r}, R_{p a r p}$ & $\begin{array}{l}\text { Parasitic resistance of inductor for real } \\
\text { parallel model }\end{array}$ \\
\hline$R_{w D C}, R_{w A C}$ & Resistance of wire in both DC/AC \\
\hline$Z_{m a x}$ & Maximum impedance \\
\hline$\omega, \omega_{0}$ & Radian / Resonance frequency \\
\hline$\delta_{w}$ & Skin depth of wire \\
\hline$\rho_{w}$ & Resistivity of wire \\
\hline$\mu_{0}$ & Permeability of air or vacuum \\
\hline$\mu_{e q}$ & Equal permeability of core \\
\hline$\mu_{r w}$ & Relative permeability of wire \\
\hline
\end{tabular}

\section{References}

[1] L. Tihanyi, "Electromagnetic Compatibility in Power Electronics", IEEE Press, New York, 1995.

[2] K. W. E. Cheng. "Computation of the AC Resistance of Multistranded Conductor Inductors with Multilayer for High Frequency Switching Converters". IEEE Tran. Magn., VOL. 36, NO. 4, 2000.

[3] R. A. Jensen, C. R. Sullivan, "Optimal Core Dimensional Ratios for Minimizing Winding Loss in High-Frequency Gapped-Inductor Windings", IEEE 078037769, 2003.

[4] J. Hu, C. R. Sullivan, "AC Resistance of Planar Power Inductors and the Quasidistributed Gap Technique", IEEE Trans. Power Electron, VOL. 16, NO. 4, 2001

[5] A. Massarini, M.K. Kazimierczuk, G. Grandi, "Lumped Parameter Models for Single- and Multiple-Layer Inductors", Pesc96 conf, 1996.

[6] Z. Ouyang, O. C. Thomsen, A. E. Andersen, " The Analysis and Comparison of Leakage Inductance in Different Winding Arrangements for Planar Transformer", PEDS, 2009.

[7] M. Bartoli, A. Reatti, M. K. Kazimierczuk, " Modeling Iron-Powder Inductors at High Frequencies", IEEE 00377550 , 1994.

[8] U. Reggiani, G. Grandi, G. Sancineto, M. K . Kazimierczuk, A. Massarini, "Model of Laminated Iron Core Inductors for High Frequencies" IEEE Tran. Magn., VOL. 40, NO. 4, JULY 2004.

[9] U. Reggiani, G. Grandi, G. Sancineto, M. K . Kazimierczuk, A. Massarini, "High Frequency Small Signal Model of Ferrite Core Inductors" IEEE Tran. Magn., VOL. 35, NO. 5, SEPT 1999.
[10] U. Reggiani, G. Grandi, G. Sancineto, A. Massarini, "Laminated iron Core Inductor Model for Time Domain Analysis" PEDS 2001, Indonesia.

[11]A. W. Barr, "Calculation of Frequency-Dependent Impedance for Conductors of Rectangular Cross Section", AMP Journal of Technology Vol. 1. 1991.

[12]H. Y. Lu, J. G. Zhu, S. Y. R. Hui, , " Experimental Determination of Stray Capacitances in High Frequency Transformers". IEEE Trans. Power Electron., VOL. 18, NO. 5, 2003.

[13]D. K. Cheng, "Field and Wave Electromagnetics". Addison Wesley Publishing Company, 1983.

[14] G. Grandi, M. K. Kazimierczuk, A. Massarini, U. Reggiani, "Stray Capacitances of Single-Layer Solenoid Air-Core Inductors", IEEE Trans. Ind. Elec., VOL. 35, NO. 5, SEPTEMBER/OCTOBER 1999.

[15]M. Mordjaoui, M.Chabane, B. Boudjema, R.Daira, "Qualitative Ferromagnetic Hysteresis Modeling", Journal of Computer Science, ISSN 1549-3636, 2007.

[16] T. C. Neugebauer. D. J. Perreault, "Parasitic Capacitance Cancellation in Filter Inductors". IEEE. Trans. Power Electronics, Vol. 21, NO. 1, January 2006, pp. 282-288.

[17] S. Wang, W. G. Odendaal, F. C. Lee, "Extraction of Parasitic Parameters of EMI Filters Using Scattering Parameters", IEEE 078038486, 2004.

[18]C. A. Desoer. E. H. Kuh, "Basic Circuit Theory". McGraw-Hill Book Company. 1969.

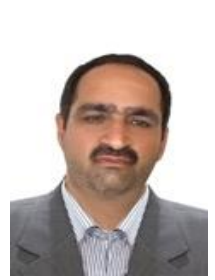

Khalil Kanzi (GSM, 2009) was born in Yazd, Iran, on March 21, 1959. He received the B.S degree from K.N. Toosi University of Technology and M. Sc. from Tarbiat Modaress University of Teheran in 1984 and 1992 respectively. He has worked for the ACECR Research Institute (K.N. Toosi University branch) in Teheran in the area of LV/HV high power electrical machines (Design and realization), power electronic and power systems for more than 17 years. He received the Ph.D. degree from K. N. Toosi University of Technology in 2010. He is now working at the ACECR Institute and his working area is design and realization of conducted EMI filters, electrical machines and FACTS controllers. 


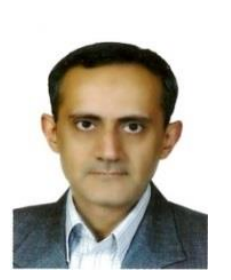

Hamidreza Nafissi born in 1966 in Tehran, Iran, received the B.Sc. and M.Sc. degrees both from K.N. Toosi University of Technology in 1988 and 1992 respectively. He used to work in the ACECR Research Institute (K.N. Toosi University branch) in Teheran since 1990. His research area included telecommunication circuits, solid-state microwave amplifiers, solid-state high-power MW broadcast transmitters, solid-state SW transmitters, solid-state high-power FM broadcast transmitters, HF high efficiency class-D amplifiers, frequency synthesizers, electronic protection circuits for transmitters, audio processing circuits, a wide variety of switching power supplies, switched mode chargers, dc-dc converters. He is now a PhD student at the Department of Electrical and Computer Engineering, University of Waterloo, Canada.

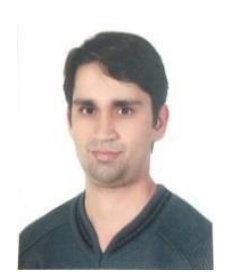

Majid Kanzi was born in 1983 in Teheran, Iran. He received the B.Sc. degree in Electrical Engineering from Islamic Azad University of Tehran and M.Sc. in Power Electronics in Kurdistan University of Iran in 2006 and 2010 respectively. Since 2004, he has been working on research area of power quality in Electrical Power Network and from 2009, on Improving Power Factor and Eliminating the EMI Noise in Switching Power Supplies. He also worked on designing and fabrication of electromechanical devices such as eddy current brake, DC counter rotating motor at the ACECR. His interesting fields are EMC/EMI, power electronic devices and FACTS controllers. 